\title{
Common Fixed Point Theorem with Refined Condition of Weak Contraction by Generalized Altering Distance Function
}

\author{
P.L. Powar \\ Rani Durgawati University, Jabalpur (M.P.) \\ Department of Mathematics and Computer Science, \\ Rani Durgawati University, Jabalpur (M.P.), India.
}

\author{
G.R.K. Sahu \\ Rani Durgawati University, Jabalpur (M.P.) \\ Department of Mathematics and Computer Science, \\ Govt. Model Science College, Jabalpur (M.P.), India.
}

\begin{abstract}
In the present paper, the authors have obtained a unique fixed point theorem for four maps using generalized altering distance function in four variables by considering a refined form of weak contraction than the form used in Theorem 2.1 of [17] which reduces the computational part quite significantly.
\end{abstract}

\section{AMS Subject Classification: 47H10;60H05;60H10}

\section{Keywords}

Fixed point, compatible of type $(\mathrm{P})$ or $(\beta)$ mappings,

Altering distance function, weak contraction.

\section{INTRODUCTION}

Banach contraction principle has been widely studied by many mathematicians during the last decades (cf. [2], [3], [4], [5], [8], [9], [10], [11], [13], [14] etc.). By considering the weak form of contractive maps, a fixed point problem was initiated by Khan in (cf. [12]). It may be noted that the concept of altering distance function was first introduction by Khan (cf. [12]).

Recently, the concept of altering distance function has become more popular and by using this concept many mathematicians tackled the fixed point problem with the aid of this new concept (cf. [1], [7], [17], [19], [20], [21]). Choudhary (cf. [7]) introduced a generalized distance function in three variables. Rao, K.P.R. et al. in 2007 (cf. [17]) have proved an interesting result by considering generalized altering distance functions of four variables and concluded that the four continuous maps have a unique common fixed point.

In the present paper, the authors have noticed that the condition (i) of Theorem 2.1 of [17] can be replaced by another general condition which significantly reduces the computational part of the proof and established the same conclusion as given in Theorem 2.1 of [17]. In particular, condition (i) of Theorem 2.1 of [17] would be a special case of the main result of this paper. It may be further noted that by choosing suitable values of the variables the result covers several other important theorems also.

\section{PRELIMINARIES}

In order to establish the main result, the following definitions are required:
Definition 2.1 Let (X, d) be a metric space. A mapping $\mathrm{T}: \mathrm{X} \longrightarrow \mathrm{X}$ is said to be weakly contractive if

$$
d(T x, T y) \leq d(x, y)-\phi d(x, y) \quad \forall x, y \in X
$$

where $\phi:[0, \infty) \rightarrow[0, \infty)$ is an altering distance function

Definition 2.2 Let $\mathrm{S}$ and $\mathrm{T}$ be two self maps on a metric space $(\mathrm{X}, \mathrm{d})$. The pair $(\mathrm{S}, \mathrm{T})$ is said to be compatible of type (P) or $(\beta)$, if $\lim d\left(S^{2} x_{n}, T^{2} x_{n}\right)=0$, whenever $\left\{\mathrm{x}_{\mathrm{n}}\right\}$ is a sequence in $\mathrm{X}$ such that $\lim \mathrm{Sx}_{\mathrm{n}}=\lim \mathrm{Tx}_{\mathrm{n}}=\mathrm{t}$ for some $t \in X$. It is clear that $S T x=T S x$, whenever $S x=T x$ for any $\mathrm{x} \in \mathrm{X}$.

Definition 2.3 Let $\psi_{n}$ denote the set of all functions $\psi:[0, \infty)^{n} \longrightarrow[0, \infty)$ such that

(i) $\quad \psi$ is continuous

(ii) $\quad \psi$ is monotonic increasing.

(iii) $\quad \psi\left(\mathrm{t}_{1}, \mathrm{t}_{2}, \ldots, \mathrm{t}_{\mathrm{n}}\right)=0 \Leftrightarrow \mathrm{t}_{1}=\mathrm{t}_{2}=\ldots=\mathrm{t}_{\mathrm{n}}=0$

The functions in $\psi_{n}$ are called generalized altering distance functions.

\section{RESULTS ALREADY PROVED}

Theorem 3.1 (cf. [7]) Let $\mathrm{S}$ and $\mathrm{T}$ be self mappings of a complete metric space $(X, d)$ satisfying

$$
\begin{gathered}
\phi_{1}(d(S x, T y)) \leq \psi_{1}(d(x, y), d(x, S x), d(y, T y)) \\
-\psi_{2}(d(x, y), d(x, S x), d(y, T y))
\end{gathered}
$$

for all $\mathrm{x}, \mathrm{y} \in \mathrm{X}$, where $\psi_{1}$ and $\psi_{2}$ are generalized altering distance functions and

$$
\phi_{1}(a)=\psi_{1}(a, a, a), \forall a \in[0, \infty) .
$$

Then $\mathrm{S}$ and $\mathrm{T}$ have a unique common fixed point in $\mathrm{X}$

Theorem 3.2 (cf. [17]) Let $\mathrm{P}, \mathrm{Q}, \mathrm{S}$ and $\mathrm{T}$ be self mappings of a complete metric space (X, d) satisfying 
(i)

$\phi_{1}(d(P x, Q y)) \leq \psi_{1}\left(d(S x, T y), d(S x, P x), d(T y, Q y), \frac{1}{2}[d(S x, Q y)+d(T y, P x)]\right)$

$-\psi_{2}\left(d(S x, T y), d(S x, P x), d(T y, Q y), \frac{1}{2}[d(S x, Q y)+d(T y, P x)]\right)$

for all $\mathrm{x}, \quad \mathrm{y} \in \mathrm{X}$, where $\psi_{1}, \quad \psi_{2} \in \psi_{4}$ and $\phi_{1}(a)=\psi_{1}(a, a, a, a), \quad \forall a \in[0, \infty)$.

(ii) Either $\mathrm{S}$ and $\mathrm{T}$ or $\mathrm{P}$ and $\mathrm{T}$ or $\mathrm{Q}$ and $\mathrm{S}$ are continuous.

(iii) $(\mathrm{P}, \mathrm{S})$ and $(\mathrm{Q}, \mathrm{T})$ are compatible pairs of type $(\beta)$.

(iv) $\mathrm{PT}(\mathrm{X}) \bigcup \mathrm{QS}(\mathrm{X}) \subseteq \mathrm{ST}(\mathrm{X})$ and $\mathrm{ST}=\mathrm{TS}$.

Then $\mathrm{P}, \mathrm{Q}, \mathrm{S}$ and $\mathrm{T}$ have a unique common fixed point in $\mathrm{X}$.

\section{MAIN RESULT}

Theorem 4.1 Let $\mathrm{P}, \mathrm{Q}, \mathrm{S}$ and $\mathrm{T}$ be self-mappings of a complete metric space $(X, d)$ satisfying

(i) $\phi_{1}(d(P x, Q y)) \leq \psi_{1}\left(d(S x, T y), r_{1}, r_{2}, r_{3}\right)-\mathrm{r}$

for all $\mathrm{x}, \mathrm{y} \in \mathrm{X}$, where $\psi_{1} \in \psi_{4}, \quad \mathrm{r} \geq 0$, $0 \leq r_{i} \leq d(P x, Q y), i=1,2,3$.

and $\phi_{1}(a)=\psi_{1}(a, a, a, a), \quad \forall a \in[0, \infty)$

(ii) Either $\mathrm{S}$ and $\mathrm{T}$ or $\mathrm{P}$ and $\mathrm{T}$ or $\mathrm{Q}$ and $\mathrm{S}$ are continuous.

(iii) $(\mathrm{P}, \mathrm{S})$ and $(\mathrm{Q}, \mathrm{T})$ are compatible pairs of type $(\beta)$.

(iv) $\mathrm{PT}(\mathrm{X}) \bigcup \mathrm{QS}(\mathrm{X}) \subseteq \mathrm{ST}(\mathrm{X})$ and $\mathrm{ST}=\mathrm{TS}$.

Then $\mathrm{P}, \mathrm{Q}, \mathrm{S}$ and $\mathrm{T}$ have a unique common fixed point in $\mathrm{X}$.

Proof. Let $\mathrm{z}$ be any arbitrary point of $\mathrm{X}$. From (iv) construct the sequences $\left\{x_{n}\right\}$ and $\left\{y_{n}\right\}$ of point of $X$ such that

$\operatorname{PTx}_{2 \mathrm{n}}=\operatorname{STx}_{2 \mathrm{n}+1}=\mathrm{y}_{2 \mathrm{n}+1}, \quad \mathrm{QSx}_{2 \mathrm{n}+1}=\operatorname{STx}_{2 \mathrm{n}+2}=\mathrm{y}_{2 \mathrm{n}+2}$, $\forall \mathrm{n}=0,1,2, \ldots$

Let $\quad a_{n}=d\left(y_{n}, y_{n+1}\right)$. Putting $x=T_{2 n}, \quad y=S_{2 n+1}$ in (i) leads to

$\phi_{1}\left(a_{2 n+1}\right) \leq \psi_{1}\left(a_{2 n}, r_{1}, r_{2}, r_{3}\right)-\mathrm{r}$

If $\mathrm{a}_{2 \mathrm{n}}<\mathrm{a}_{2 \mathrm{n}+1}$, then

$$
\begin{aligned}
& \phi_{1}\left(a_{2 n+1}\right) \leq \psi_{1}\left(a_{2 n+1}, a_{2 n+1}, a_{2 n+1}, a_{2 n+1}\right)-\mathrm{r} \\
& \quad<\psi_{1}\left(a_{2 n+1}, a_{2 n+1}, a_{2 n+1}, a_{2 n+1}\right)=\phi_{1}\left(a_{2 n+1}\right)
\end{aligned}
$$

which is a contradiction. Hence $\mathrm{a}_{2 \mathrm{n}+1} \leq \mathrm{a}_{2 \mathrm{n}}, \forall \mathrm{n}=0,1,2 \ldots$ Similarly, by putting $\mathrm{x}=\mathrm{Tx}_{2 \mathrm{n}}, \mathrm{y}=\mathrm{Sx}_{2 \mathrm{n}-1}$, in (i) it has been obtained that $a_{2 n} \leq a_{2 n-1}, \forall \mathrm{n}=1,2, \ldots$

Thus, $a_{n+1} \leq a_{n}, \forall \mathrm{n}=1,2, \ldots$, so that $\left\{\mathrm{a}_{\mathrm{n}}\right\}$ is monotonically decreasing sequence of non-negative real numbers and hence converges to a point $\mathrm{a} \in \mathrm{R}$.

Now, letting $n \rightarrow \infty$, (4.1) reduces to

$$
\begin{aligned}
\phi_{1}(a) & \leq \psi_{1}(a, 0,0,0)-\mathrm{r} \\
& \leq \psi_{1}(a, a, a, a)-\mathrm{r}=\phi_{1}(a), \text { if } \quad \mathrm{a}>0
\end{aligned}
$$

Thus, $\phi_{1}(a)<\phi_{1}(a)$, which is a contradiction, therefore $a=0$ Hence, $\lim d\left(y_{n}, y_{n+1}\right)=\lim a_{n}=0$

To show that the sequence $\left\{\mathrm{y}_{\mathrm{n}}\right\}$ is a Cauchy sequence, it is sufficient to show that the subsequence $\left\{\mathrm{y}_{2 \mathrm{n}}\right\}$ of $\left\{\mathrm{y}_{\mathrm{n}}\right\}$ is a Cauchy sequence in view of (4.2).

Suppose, if possible, the sequence $\left\{\mathrm{y}_{2 \mathrm{n}}\right\}$ is not a Cauchy sequence. Then, there exists an $\in>0$ and monotonically increasing sequences of natural numbers $\{2 \mathrm{~m}(\mathrm{k})\}$ and $\{2 \mathrm{n}(\mathrm{k})\}$ such that $\mathrm{n}(\mathrm{k})>\mathrm{m}(\mathrm{k})$,

$$
\begin{aligned}
& \mathrm{d}\left(\mathrm{y}_{2 \mathrm{~m}(\mathrm{k})}, \mathrm{y}_{2 \mathrm{n}(\mathrm{k})}\right) \geq \in \text { and } \mathrm{d}\left(\mathrm{y}_{2 \mathrm{~m}(\mathrm{k})}, \mathrm{y}_{2 \mathrm{n}(\mathrm{k})-1}\right)<\in \\
& \in \leq d\left(y_{2 m(k)}, y_{2 n(k)}\right) \\
& \leq d\left(y_{2 m(k)}, y_{2 n(k)-1}\right)+d\left(y_{2 n(k)-1}, y_{2 n(k)}\right) \\
& <\in+d\left(y_{2 n(k)-1}, y_{2 n(k)}\right) \quad \text { (using (4) }
\end{aligned}
$$

Letting $n \rightarrow \infty$ and using (4.2), it may be noted that $\lim d\left(y_{2 n(k)}, y_{2 m(k)}\right)=\in$

Letting $n \rightarrow \infty$, using (4.2) and (4.4) in

$$
\begin{aligned}
& \left|d\left(y_{2 n(k)+1}, y_{2 m(k)}\right)-d\left(y_{2 n(k)}, y_{2 m(k)}\right)\right| \\
& \leq d\left(y_{2 n(k)}, y_{2 n(k)+1}\right)
\end{aligned}
$$

we have, $\quad \lim d\left(y_{2 n(k)+1}, y_{2 m(k)}\right)=\epsilon$

Similarly letting $n \rightarrow \infty$ and using (4.2) and (4.4) in

$$
\begin{aligned}
& \left|d\left(y_{2 n(k)}, y_{2 m(k)-1}\right)-d\left(y_{2 n(k)}, y_{2 m(k)}\right)\right| \\
& \leq d\left(y_{2 m(k)}, y_{2 m(k)-1}\right),
\end{aligned}
$$

it has been obtained that,

$$
\lim d\left(y_{2 n(k)}, y_{2 m(k)-1}\right)=\in
$$

Putting $\quad \mathrm{x}=\mathrm{Tx}_{2 \mathrm{n}(\mathrm{k}),} \quad \mathrm{y}=\mathrm{Sx}_{2 \mathrm{~m}(\mathrm{k})-1}$ in (i), leads to

$$
\begin{aligned}
& \phi_{1}\left(d\left(y_{2 n(k)+1}, y_{2 m(k)}\right)\right) \\
& \leq \psi_{1}\left(d\left(y_{2 n(k)}, y_{2 m(k)-1}\right), r_{1}, r_{2}, r_{3}\right)_{-\mathrm{r}}
\end{aligned}
$$

Letting $k \rightarrow \infty$ and using (4.4) and (4.6), it may be noted that

$$
\begin{aligned}
\phi_{1}(\in) & \leq \psi_{1}(\in, 0,0,0)-\mathrm{r} \\
& <\psi_{1}(\in, \in, \in, \in)=\phi_{1}(\in)
\end{aligned}
$$

Which is a contradiction. Therefore, $\left\{y_{2 n}\right\}$ is a Cauchy sequence and hence $\left\{y_{n}\right\}$ is a Cauchy sequence. Since $X$ is complete, there exists $\mathrm{z} \in \mathrm{X}$ such that $\mathrm{y}_{\mathrm{n}} \rightarrow \mathrm{z}$ as $\mathrm{n} \rightarrow \infty$.

Let $\operatorname{Tx}_{2 \mathrm{n}}=\mathrm{v}_{\mathrm{n}}, \quad \mathrm{Sx}_{2 \mathrm{n}+1}=\mathrm{w}_{\mathrm{n}+1}, \quad \forall \mathrm{n}$

Then, $\mathrm{Pv}_{\mathrm{n}} \rightarrow \mathrm{z}, \quad \mathrm{Sv}_{\mathrm{n}} \rightarrow \mathrm{z}, \mathrm{Qw}_{\mathrm{n}+1} \rightarrow \mathrm{z}$ and $\mathrm{Tw}_{\mathrm{n}+1} \rightarrow \mathrm{z}$. 
Case I. Suppose $\mathrm{S}$ and $\mathrm{T}$ are continuous.

Step 1. Since $S$ is continuous, $\mathrm{SP}_{\mathrm{n}} \rightarrow \mathrm{Sz}, \quad \mathrm{S}^{2} \mathrm{v}_{\mathrm{n}} \rightarrow \mathrm{Sz}$. Since $(P, S)$ is compatible of type $(\beta)$, hence $P^{2} v_{n} \rightarrow$ Sz.

Suppose $\mathrm{Sz} \neq \mathrm{z}$.

Putting $\mathrm{x}=\mathrm{Pv}_{\mathrm{n}}, \mathrm{y}=\mathrm{w}_{\mathrm{n}+1}$ in (i), yields

$\phi_{1}\left(d\left(P^{2} v_{n}, Q w_{n+1}\right)\right)$

$\leq \psi_{1}\left(d\left(S P v_{n}, T w_{n+1}\right), r_{1}, r_{2}, r_{3}\right)_{-\mathrm{r}}$

Letting $n \rightarrow \infty$, it may be noted

$$
\begin{aligned}
& \phi_{1}(d(S z, z)) \leq \psi_{1}(d(S z, z), 0,0,0)-\mathrm{r} \\
& <\psi_{1}(d(S z, z), d(S z, z), d(S z, z), d(S z, z)) \\
& \quad=\phi_{1}(d(S z, z))
\end{aligned}
$$

It is a contradiction, hence $\mathrm{Sz}=\mathrm{z}$.

Putting $\mathrm{x}=\mathrm{z}, \mathrm{y}=\mathrm{w}_{\mathrm{n}+1}$ in (i) and letting $n \rightarrow \infty$ gives, $\mathrm{Pz}=\mathrm{z}$.

Step 2. Since $\mathrm{T}$ is continuous, we have $\mathrm{TQw}_{\mathrm{n}+1} \rightarrow \mathrm{Tz}$, $\mathrm{T}^{2} \mathrm{w}_{\mathrm{n}+1} \rightarrow \mathrm{Tz}$. Since $(\mathrm{Q}, \mathrm{T})$ is compatible of type $(\beta)$, leads to have $\mathrm{Q}^{2} \mathrm{w}_{\mathrm{n}+1} \rightarrow$ Tz. Putting $\mathrm{x}=\mathrm{v}_{\mathrm{n}}, \mathrm{y}=\mathrm{Qw}_{\mathrm{n}+1}$ in (i) and letting $n \rightarrow \infty \Rightarrow \mathrm{Tz}=\mathrm{z}$. Again substituting $\mathrm{x}=\mathrm{v}_{\mathrm{n}}, \quad \mathrm{y}=$ $\mathrm{z}$ in (i) and letting $n \rightarrow \infty \Rightarrow \mathrm{Qz}=\mathrm{z}$.

Thus, $\quad \mathrm{Pz}=\mathrm{Qz}=\mathrm{Sz}=\mathrm{Tz}=\mathrm{z}$.

Case II. Suppose $\mathrm{P}$ and $\mathrm{T}$ are continuous. From step 2, it may be observed that $\mathrm{Tz}=\mathrm{Qz}=\mathrm{z}$.

Step 3. Since $\mathrm{P}$ is continuous, implies $\mathrm{PSv}_{\mathrm{n}} \rightarrow \mathrm{Pz}$ and $\mathrm{P}^{2} \mathrm{v}_{\mathrm{n}} \rightarrow \mathrm{Pz}$. Since $(\mathrm{P}, \mathrm{S})$ is compatible of type $(\beta)$, we get $\mathrm{S}^{2} \mathrm{v}_{\mathrm{n}} \rightarrow$ Pz. Putting $\mathrm{x}=\mathrm{Sv}_{\mathrm{n}}, \mathrm{y}=\mathrm{w}_{\mathrm{n}+1}$ in (i) and letting $n \rightarrow \infty$, yields $\mathrm{Pz}=\mathrm{z}$.

Step 4. Now $\mathrm{PTz}=\mathrm{Pz}=\mathrm{z}$. Since $\mathrm{PT}(\mathrm{X}) \subseteq \mathrm{ST}(\mathrm{X})$, there exists $\mathrm{u} \in \mathrm{X} \quad$ such that $\mathrm{PTz}=\mathrm{STu}$. Let $\mathrm{Tu}=\mathrm{v}$ so that $\mathrm{z}=\mathrm{PTz}=\mathrm{STu}=\mathrm{Sv}$.

Suppose $\operatorname{Pv} \neq \mathrm{z}$

$$
\begin{aligned}
& \text { Putting } \begin{aligned}
& \mathrm{x}=\mathrm{v}, \quad \mathrm{y}=\mathrm{z} \text { in (i), leads to } \\
& \phi_{1}(d(P v, z))=\phi_{1}(d(P v, Q z)) \\
& \leq \psi_{1}\left(d(S v, T z), r_{1}, r_{2}, r_{3}\right)-\mathrm{r} \\
&=\psi_{1}\left(0, r_{1}, r_{2}, r_{3}\right)-\mathrm{r} \\
& \leq \psi_{1}(d(P v, z), d(P v, z), d(P v, z), d(P v, z))-\mathrm{r} \\
&<\psi_{1}(d(P v, z), d(P v, z), d(P v, z), d(P v, z)) \\
&=\phi_{1}(d(P v, z))
\end{aligned}
\end{aligned}
$$

It is a contradiction. Hence $\mathrm{Pv}=\mathrm{z}$. Since $\mathrm{Pv}=\mathrm{Sv}=\mathrm{z}$ and $(P, S)$ is compatible of type $(\beta)$, gives $P z=S z$.

Thus, $\quad \mathrm{Pz}=\mathrm{Qz}=\mathrm{Tz}=\mathrm{Sz}=\mathrm{z}$.

Case III. Suppose $\mathrm{Q}$ and $\mathrm{S}$ are continuous. From step 1, it implies $\mathrm{Sz}=\mathrm{Pz}=\mathrm{z}$. As in step 3, it may be concluded that $\mathrm{Qz}$
= z. Since $\mathrm{QS}(\mathrm{X}) \subseteq \mathrm{ST}(\mathrm{X})$, as in step 4, leads to $\mathrm{Qz}=\mathrm{Tz}$. Thus, $\mathrm{Pz}=\mathrm{Qz}=\mathrm{Sz}=\mathrm{Tz}=\mathrm{z}$.

Uniqueness of the common fixed point follows easily from (i).

\section{CONCLUSION}

Considering, $r_{1}=d(S x, P x), r_{2}=d(T y, Q y)$

$r_{3}=\frac{1}{2}[d(S x, Q y)+d(T y, P x)]$ and

$\mathrm{r}=\psi_{2}\left(d(S x, T y), d(S x, P x), d(T y, Q y), \frac{1}{2}[d(S x, Q y)+d(T y, P x)]\right)$

The result of Rao K.P.R. et. al. [17] may be obtained.

Since, the parameters $r_{1}, r_{2}, r_{3}$ and $r$ are left arbitrary, one may select these according to the demand of applications, for example; in the solution of differential equations.

\section{ACKNOWLEDGMENTS}

The authors would like to thank referees of this paper for their helpful suggestions.

The second author would like to thank University Grants Commission for supporting this work under the teacher fellowship program.

\section{REFERENCES}

[1] Abbas, M., Ali Khan, M., Common fixed point theorem of two mappings satisfying a generalized weak contractive conditions. Int. J. Math. Sci. 2009, 9 Article ID 131068 (2009).

[2] Agarwal, R.P., El-Gebeily, M.A., O'Regan, D., Generalized contractions in partially ordered metric space. Appl. Anal. 87, 109-116 (2008).

[3] Alber, YaI, Guerre-Delabriere, S., Principles of weakly contractive maps in Hilber spaces. Oper Theory. Adv. Appl. 98, 7-22 (1997).

[4] Babu, G.V.R. and Shaik Ismail, A fixed point theorem by altering distances, Bull Cal. Math Soc, 93(5), 393-398, (2001).

[5] Babu, G.V.R. Generalization of fixed point theorems relating to the diameter of orbits by using a control function, Tamkang J. Math, 35(2), 159-168 (2004).

[6] Banach, S., Surles operations dans les ensembles abstraits et leur application aux equationsitegrales, Fund. Math., 3, 133-181, (1922).

[7] Choudhury, B.S., A common unique fixed point result in metric spaces involving generalized altering distances, Math. Commun. 10, 105-110 (2005).

[8] Choudhury, B.S. and Dutta, P.N., A unified fixed point result in metric spaces involving a two variable function, Filomat, 14, 43-48 (2000).

[9] Dutta, P.N., Choudhury, B.S., A generalization of contraction principles in metric spaces, Fixed Point Theory Appl. 2008, 8 Article ID 406368 (2008).

[10] Fisher, B., A common fixed point theorem for commuting mappings, Math. Sem. Notes, 7, 297-300, (1979). 
[11] Jungck, G., Murthy, P.P., Cho, Y.J., Compatible mappings of type (A) and common fixed points, Math. Japonica, 38, 381-390, (1993).

[12] Khan, M.S., Swalesh, M. Sessa, S., Fixed point theorems by altering distances between the points. Bull. Aust. Math. Soc. 30, 1-9 (1984).

[13] Murthy, P.P., Important tools and possible applications of metric fixed point theory, Nonlinear analysis 47, 3479-3490 (2001).

[14] Murthy, P.P., Cho, Y.J., Fisher, B., Common fixed points of Gregus type mappings, Glasnik Mathematicki, 30, 335-341, (1995).

[15] O'Regan, D., Petrusel, A., Fixed point theorems for generalize contractions in ordered metric spaces. J. Math. Anal Appl. 341, 1241-1252 (2008).

[16] Pathak, H.K, Cho, Y.J., Kang, S.M., Remarks on Rweakly commuting mappings and Common fixed point theorem, Bull. Korean Math. Soc., 34, 247-257, (1997).
[17] Rao, K.P.R., Babu A. Som, Babu D Vasu, Common fixed points through Generalized altering distance function. Intenational mathematical forum, 2, no.65, 3233-3239, (2007)

[18] Rhoades, B.E., Some theorems on weakly contractive maps, Nonlinear Anal, 47, 2683-2693 (2001).

[19] Sastry K.P.R., Naidu, S.V.R, Babu, G.V.R. and Naidu, G.A., Generalization of common fixed point theorems for weakly commuting maps by altering distances. Tamkang J Math 31, 243-250 (2000).

[20] Sastry K.P.R. and Babu, G.V.R., Some fixed point theorems by altering distances between the points, Indian J. Pure Appl. Math. 30(6), 641-647 (1999).

[21] Sastry, K.P.R. and Babu, G.V.R.. Fixed point theorems in metric spaces by altering distances, Bull. Cal. Math. Soc. 90, 175-182 (1998)

[22] Zhang, Q., Song, Y, Fixed point theory for generalized $\varphi$-weakly contraction. Appl. Math. Lett. 22, 75-78, (2009). 